\title{
Achieving Sustainable Mobility in Developing Countries: Suggestions for a Post-2012 Agreement
}

\author{
Further rapid motorisation of developing countries \\ could counteract climate efforts and aggravate problems of \\ noxious emissions, noise, and traffic congestion. Which provisions \\ should a global climate change agreement include for reducing \\ transport-related $\mathrm{CO}_{2}$ emissions in developing countries?
}

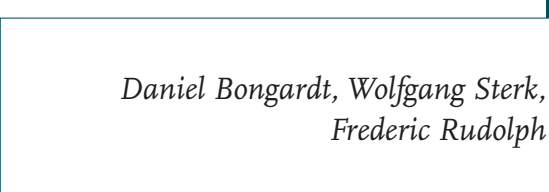

\section{Achieving Sustainable Mobility in Developing Countries: Suggestions for a Post-2012 Agreement GAIA 18/4 (2009): 307-314}

\begin{abstract}
In December 2009, countries meet in Copenhagen to establish a new global climate agreement. This article links the need for reducing transport-related greenhouse gas emissions in developing countries with the current international climate negotiations. Arguing that a sustainable transport approach requires comprehensive policy packages, it assesses the suitability of current climate negotiation proposals in promoting sustainable transport. The project-based approach under the current climate regime incentivises neither comprehensive sustainable transport and mobility policies, nor sufficient numbers of local projects. Current proposals to increase efforts by developing countries, to reform the Clean Development Mechanism, and to create new emission trading mechanisms are promising but still have to overcome several obstacles. One obstacle involves how to properly assess the impact of actions while maintaining streamlined procedures. The authors conclude from their analysis that the best way forward would be to establish an international mitigation fund with a dedicated transport window financed by industrialised countries. This fund would enable developing countries to implement national policies and local projects. Developing countries would outline low-carbon development strategies, including a sectoral strategy for low-carbon transport.
\end{abstract}

Keywords

climate change, developing countries, international climate regime, mobility, post-2012 agreement, transport nder the Kyoto Protocol (UN 1998), developed countries (socalled Annex I countries) have committed to legally binding limitation and reduction targets for greenhouse gas (GHG) emissions for the first commitment period, 2008 to 2012. Negotiations are currently underway for a new climate protection agreement post-2012, to be adopted at the climate conference scheduled for Copenhagen in December 2009. Apart from new targets for Annex I countries, negotiators are also discussing increased climate protection efforts by developing countries (non-Annex I countries), which are not subject to binding commitments under the Kyoto Protocol.

Tackling the GHG emissions of the transport sector is one of the main challenges: Transport accounts for 13.1 percent of global GHG emissions (IPCC 2007a). ${ }^{1}$ This translates to 18 percent of global carbon dioxide $\left(\mathrm{CO}_{2}\right)$ emissions and 24 percent of energy-related $\mathrm{CO}_{2}$ emissions ${ }^{2}$ (IEA 2008a), and the share is growing. The International Energy Agency (IEA) in its 2008 energy outlook (IEA 2008b) points out that it is vital to include the transport sec-

\footnotetext{
1 This includes international aviation and maritime bunkers (shipping) as well as transport-related electricity emissions (mainly for rail transport). Emissions from vehicle manufacture, road and railroad construction, etc., are not included.

2 Energy consumption is the most important reason for the contribution of transport to the anthropogenic greenhouse gas effect. The combustion of fossil fuels for energy use leads to $\mathrm{CO}_{2}$ emissions and, to a minor degree, other $\mathrm{GHC}$ emissions. Non energy-related $\mathrm{GHG}$ emissions in the transport sector primarily result from vehicle air conditioning, which is the second most important transport-related reason for global warming (IPCC 2007b). Vehicle air conditioning is often operated with $\mathrm{GHG}$ s other than $\mathrm{CO}_{2}$, namely, nitrous oxide $\left(\mathrm{N}_{2} \mathrm{O}\right)$, methane $\left(\mathrm{CH}_{4}\right)$, and fluorocarbons ( $\mathrm{F}$ gases). Aviation has a larger impact on radiative forcing (i. e., global warming) than that caused by its (energy-related) $\mathrm{CO}_{2}$ emissions alone since emissions of nitrogen oxides $\left(\mathrm{NO}_{\mathrm{x}}\right)$, water vapour, and particulates at altitude account for extra impacts.
}

Contact: Dipl.-Soz.-Wiss. Daniel Bongardt | Deutsche Gesellschaft für Technische Zusammenarbeit (GTZ) GmbH (German Technical Cooperation) | Division 44 - Water, Energy, Transport | Postfach 5180 | 65726 Eschborn | Germany | Tel.: +496196791375 | E-Mail: daniel.bongardt@gtz.de
Wolfgang Sterk, M. A. | E-Mail: wolfgang.sterk@wupperinst.org Dipl.-Ing. Frederic Rudolph | E-Mail: frederic.rudolph@wupperinst.org both: Wuppertal Institute for Climate, Environment, Energy | Wuppertal | Germany 


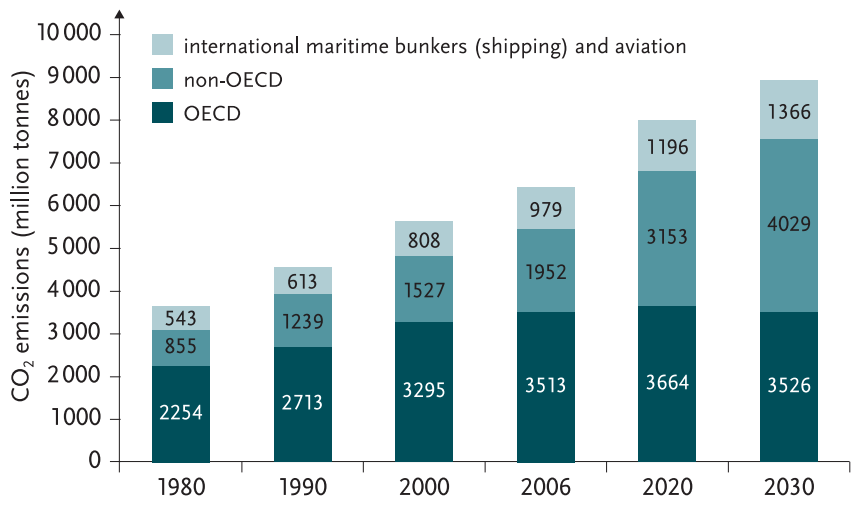

FIGURE 1: $\mathrm{CO}_{2}$ emissions from fuel combustion in the transport sector in the World Energy Outlook Reference Scenario of the International Energy Agency (IEA) The transport sector is a major source for global $\mathrm{CO}_{2}$ emissions. The share of $\mathrm{CO}_{2}$ emitted by emerging economies and developing countries is increasing. Source: own chart, based on IEA (2008b, p. 393, Table 16.4, (C) OECD/IEA).

tor in efforts to reduce GHG emissions from fuel combustion if the increase in the global mean temperature is to be kept below $2{ }^{\circ} \mathrm{C}$ compared to pre-industrial temperatures, as called for by the European Union and other countries.

How can the post-2012 agreement facilitate the development of low-emission transport systems in developing countries? To answer this question, we start by looking at the climate impact of transport and the current status of transport in the international climate regime. Then we provide an overview of the approaches needed to steer transport in a more sustainable direction. At the heart of the article lies an analysis of the current status of the negotiations, what elements of the emerging post-2012 deal are already visible, and how these might be used in relation to transport in developing countries and emerging economies. We conclude with recommendations for the design of the post-2012 regime from a sustainable transport perspective.

\section{Transport and Climate Change}

The emission share of transport in emerging economies and developing countries is still rather small but growing apace (figure 1). Between 1990 and 2007, transport-related $\mathrm{CO}_{2}$ emissions from non-Annex I countries rose by 4.4 percent per annum (IEA 2008a). It is expected that by 2025 transport-related $\mathrm{CO}_{2}$ emissions from developing countries will exceed those from industrialised countries.

Climate protection is just one of many aspects of a sustainable transport system. Air pollution and noise are currently the most pressing issues in developing countries' transport policy. Nonetheless, the problems are interrelated. Transport development in North America and Europe has shown that decisions on housing sprawl and car-friendly cities lead to more cars, more trips, and longer distances travelled. Once in place, such land use patterns are very difficult and costly to change, and the impact on future GHG emissions will be huge. Taking into account the rapid motorisation caused by urbanisation and growing income, the urgent need for transport-related action in developing countries becomes evident.

\section{Current Status of Transport in the International Climate Regime}

While individual sectors are mentioned in the United Nations Framework Convention on Climate Change UNFCCC (UN 1992) and the Kyoto Protocol, the international climate regime as yet contains no approaches or instruments addressing specific sources or sectors of GHG emissions such as transport - with the exception of land use, land use change, and forestry. Instead, the parties opted for a "targets and timetables" approach covering total emissions: Industrialised countries agreed legally binding targets for their total national emissions in the period 2008 to 2012, and it was left to their discretion in which sectors and by what measures they would reduce emissions to meet these targets. Hence, emissions from domestic transportation (including domestic aviation and shipping) in industrialised countries are included in national emission reduction targets. ${ }^{3}$

Developing countries have not yet had to assume legally binding emission reduction obligations. There are, however, two mechanisms whereby developing countries are involved in such activities:

1. the UNFCCC's financial mechanism, which is operated by the Global Environment Facility (GEF). The GEF is the designated financial operator for several multilateral environmental agreements and assists countries in meeting their emission reduction obligations under the conventions they have ratified. The GEF UNFCCC Trust Fund includes a programme on sustainable transportation projects under the budget line for climate change mitigation. Until now, the GEF has approved 166 million USD (triggering 2.1 billion USD co-funding) for 23 transport projects that include bus rapid transit (UNFCCC 2007, p. 164).

2. the Clean Development Mechanism (CDM), which is an arrangement under the Kyoto Protocol. It allows industrialised countries with a GHG reduction commitment to invest in projects that reduce emissions in developing countries as an alternative to domestic emission reductions. In contrast to the GEF, which is a fund-based mechanism financed by governments, the CDM is a project-based emission trading mechanism: Under the CDM, project developers may devise projects that reduce GHG emissions and submit them for approval by the competent national and international authorities. Once a project has completed a pre-determined first project cycle, the project developer receives emission credits, known as Certified Emission Reductions (CER). Each tonne of $\mathrm{CO}_{2}$ equivalent emissions saved by a project is worth one CER. Industrialised

\footnotetext{
3 Due to their international character, international aviation and shipping are not included in industrialised countries' emission targets. They have to be addressed at global level, and sectoral agreements might be necessary.
} 
countries can then purchase these CERs and count them towards their Kyoto targets. So far, the CDM has failed to foster transport-related project activities. As of October 2009, only two out of 1854 registered CDM projects are transport projects. There are seven transport projects in the pipeline (UNFCCC 2009).

The GEF provides the agreed incremental costs that result from developing countries' implementation of the relevant agreement. For the UNFCCC, the GEF has defined incremental costs as the difference between the full costs of the measures taken and the so-called baseline, i. e., the sum of the costs of the least expensive way to deliver an equivalent economic benefit plus the shortterm benefits to the local economy that would result from the proposed measure (GEF 1993, p. 31).

CDM project registration has a similar criterion. Projects have to be "additional", i. e., they would not have occurred without the $\mathrm{CDM}$. This means that project participants have to demonstrate that the revenue from selling CERs is needed to implement the project or that registration under the CDM helps the project overcome barriers that would otherwise prevent implementation. For example, registration under the CDM may make it easier to secure loans. Another criterion for both GEF and CDM projects is to calculate emission reductions. To determine the emission reductions, the investment that would be made and/or the business approach that would be taken in the absence of the project (known as the reference scenario) have to be identified. The project developer has to estimate the emissions that would result if the reference scenario occurred. This estimate is known as the baseline; it is compared with a forecast of the emissions that would occur if the project activity was implemented (Sterk and Arens 2008).

The requirement to define incremental costs or to demonstrate "additionality" increases the complexity of operation. Projects have to be judged against a hypothetical baseline that cannot be observed in reality. This is both difficult and subjective. The definition of incremental costs is considered one of the main reasons for delays in the submission and approval of GEF projects and is often criticised by developing countries (Yamin and Depledge 2004). The demonstration of additionality is subject to strong criticism, too. For instance, as transport is a key function of urban life (figure 2), it is rather difficult to show that a project would not have been carried out without the CDM.

Moreover, calculations to determine the emission reductions need reliable raw data, something that is particularly difficult for transport projects, since the comparison of baseline and project emissions has to account for a high number of small and mobile emission sources. The complexity will increase if one considers factors such as changes in land use or driving behaviour. The required calculations thus face a range of methodological difficulties (Wittneben et al. 2009, Sanchez 2008). In addition, financial support by the CDM in transport projects usually covers just a fraction of total project costs, generally less than two percent (Sanchez 2008).

\section{Policy Packages for Sustainable Transport}

In order to reduce $\mathrm{CO}_{2}$ emissions from the transport sector, a comprehensive set of policies is needed at different levels, from national to local (Höhne et al. 2008). Such policies are well known, and a number of good practice examples show the options for policy makers in developing countries (GTZ 2007). Policy packages for sustainable transport must include approaches that target space and infrastructure (which predetermines behaviour), behavioural preferences, and technology (Kern 1997). Policies to implement these approaches include investments, financial incentives, and regulations (see table, p. 310).

In general, two major strategies can make transportation systems more energy-efficient:

- reducing transportation needs and promoting a shift from energy-intensive transport modes to more energy-efficient modes (system efficiency approach);

- improving motor vehicle technology (vehicle efficiency approach).

Both strategies are needed. While technological approaches imply short-term measures, system-related measures need a longterm perspective. As the term "strategy" suggests, not a single policy but a policy package is needed for each strategy to achieve better environmental performance of transport systems. The table shows the range of policy options and linkages to be used to design effective packages for both strategic approaches. In order to design feasible policy packages, the institutional setting requires further differentiation along levels (national vs. local) and subsectors (passenger vs. goods transport).

At national level, decision makers can mainly influence vehicle energy efficiency and modal shifts (shifts toward more energy-efficient transport modes). The former can be fostered by tax-

FIGURE 2: The Kyoto Protocol's Clean Development Mechanism (CDM) provides funds to projects that reduce $\mathrm{CO}_{2}$ emissions in developing countries. However, the CDM in its present form is not suitable for transport projects: Projects are only supported if project participants demonstrate that their project would not be implemented without the CDM. As transport is a key function of urban life, it is rather difficult to show that a project would not have been carried out without the CDM.

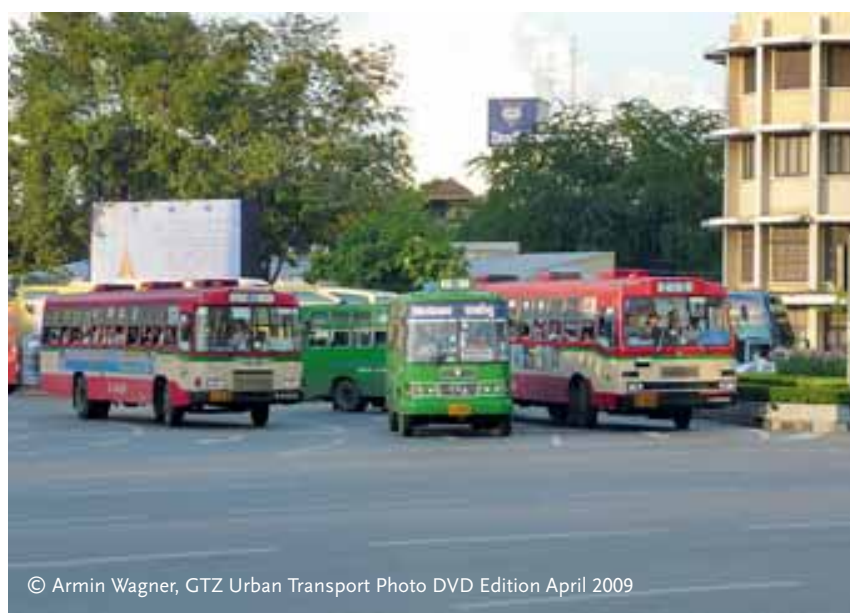


TABLE: Policy packages for sustainable transport. Strategic approaches can focus on transport system efficiency (primarily infrastructure- and behaviour-centred measures) or on vehicle efficiency (primarily technology-centred measures). Measures can be of three types: public investment, economic incentive, or regulation.

\begin{tabular}{|c|c|c|c|}
\hline $\begin{array}{l}\text { strategic approach/ } \\
\text { type }\end{array}$ & transport system & $\begin{array}{l}\text { fficiency approach } \\
\text { behaviour-centred }\end{array}$ & $\begin{array}{l}\text { vehicle efficiency approach } \\
\text { technology-centred }\end{array}$ \\
\hline public investments & $\begin{array}{l}\text { national: limitation of highway and } \\
\text { airport construction } \\
\text { national and local: investments in } \\
\text { public and non-motorised transport }\end{array}$ & $\begin{array}{l}\text { national: information and communica- } \\
\text { tion technologies in public transport } \\
\text { local: communication strategies for } \\
\text { public and non-motorised transport }\end{array}$ & $\begin{array}{l}\text { national: spending for research and develop- } \\
\text { ment of clean technologies } \\
\text { local: procurement of clean vehicles; } \\
\text { electronic ticketing }\end{array}$ \\
\hline economic incentives & $\begin{array}{l}\text { national and local: financial support } \\
\text { (taxes, tax discounts) for compact cities; } \\
\text { non traffic-intensive land use }\end{array}$ & $\begin{array}{l}\text { national: energy taxes } \\
\text { local: parking fees; ticket pricing; } \\
\text { city tolls }\end{array}$ & $\begin{array}{l}\text { national: tax incentives for clean technologies } \\
\text { national and local: toll exemption for clean } \\
\text { vehicles }\end{array}$ \\
\hline regulations & $\begin{array}{l}\text { national and local: active land use } \\
\text { planning; rules for compact cities and } \\
\text { environmental impact assessment }\end{array}$ & $\begin{array}{l}\text { national: speed limits, eco-driving as a } \\
\text { requirement in driving lessons } \\
\text { local: parking restrictions; car access } \\
\text { restrictions; car-free days }\end{array}$ & $\begin{array}{l}\text { national: standards for phasing in best avail- } \\
\text { able technique; quota for alternative fuels } \\
\text { local: spatial bans of dirty vehicles; } \\
\text { low-emission zones }\end{array}$ \\
\hline
\end{tabular}

es, speed limits, or road tolls; the latter can be facilitated by allocating funding to low-carbon infrastructure investments. At local level, decision makers can mostly influence modal shifts and transportation needs. Transport and urban planning is an opportunity to adjust and specify the policy elements needed to substantially reduce greenhouse gas emissions and further negative environmental impacts. Planning processes include a mid-term perspective and can also refer to different policy levels, e. g., urban planning can anticipate rising national energy taxes.

\section{Analysis of the UNFCCC Negotiations from a Sustainable Transport Perspective}

\section{Configuration of the UNFCCC Negotiations}

From the outset, the international climate negotiations have been shaped by a deep conflict on effort sharing: Who should take action, when should it be taken, and to what extent? The UNFCCC lays down the basic principles of effort sharing:

"The Parties should protect the climate system (...) on the basis of equity and in accordance with their common but differentiated responsibilities and respective capabilities. Accordingly, the developed country Parties should take the lead in combating climate change and the adverse affects thereof." (UN 1992, Art. 3)

In addition, the UNFCCC commits industrialised countries to covering the "agreed full incremental costs" of actions taken by developing countries (Art. 4.3). The basic parameters for the negotiations on the future of the climate regime were set at the climate conference in Bali in 2007. Beside further reductions by industrialised countries, the Bali Action Plan (UNFCCC 2008) calls for "nationally appropriate mitigation actions by developing country Parties in the context of sustainable development, supported and enabled by technology, financing and capacity-building, in a measurable, reportable and verifiable manner." The Bali Action Plan raised the bar significantly for both sides: For developing countries, the debate has shifted from qualitative commitments to quantifiable mitigation actions. For developed countries, it also constitutes a relevant change from the past, where support for developing countries was mainly delivered through voluntary contributions to funds, and where any technology transferred was not measurable. With the Bali Action Plan, developing countries are supposed to undertake quantifiable nationally appropriate mitigation actions (NAMAs), and these are to be supported by developed countries in an equally quantifiable manner.

\section{Assessment of Proposals of Parties under the UNFCCC}

The negotiations have produced various proposals relevant to this paper. In essence this involves 1. proposals for increased efforts by developing countries in the form of NAMAs, 2. proposals to reform the CDM, and 3. proposals to introduce new emission trading mechanisms. In the following, we will assess the potential of these proposals for increased transport sector involvement in mitigation activities.

\section{Nationally Appropriate Mitigation Actions}

A clear consensus on the exact nature of NAMAs and mechanisms for support has yet to emerge. But it is clear that a NAMA can be any action that reduces emissions, from introducing a new policy to implementing a concrete investment at local level. There seems to be growing consensus that NAMAs should be entered into some form of international registry. Where necessary, this registry could also be used as a platform to link actions by the South with resources from the North. The EU has proposed that NAMAs should not be seen individually but put into a comprehensive framework of "low-carbon development strategies", which would allow assessment of a country's overall level of ambition.

The proposal to internationally register and support specific policies and measures can easily be conceived as a vehicle to promote sustainable transport policies. The challenge is to determine both the kind of international support required and appropriate monitoring, reporting, and verification of the emission reductions that have been achieved. Policies typically intervene in complex environments, and it is difficult to factor out the signal (i.e., the policy) from the noise (i.e., other factors such as changes in fuel prices). 
Comprehensive national low-carbon development plans and strategies could outline comprehensive policy packages. To include transport in these strategies, it is important to mention the transport sector explicitly in the Copenhagen agreement. Also, as transport is not an homogeneous sector, defining subsectors (e. g., urban transport) and subsectoral policy packages may be necessary.

For each of these policy packages, a (simplified) methodology able to evaluate its climate impact would have to be drafted and agreed. So even if the concrete policies summarised in one package are different from country to country, the methodology to measure the emission reductions would be the same or based on the same principles. This approach would facilitate measuring, reporting, and verification of NAMAs to a great extent.

To avoid a repetition of the problems encountered by the GEF and the CDM, it might be wise to separate the assessment of emissions and of the implementation of actions. Emissions could be assessed at aggregate level using robust national emission inventories. Conversely, NAMAs could be assessed not for their emission impact but for their implementation. The Conference of the Parties could develop guidelines on what constitutes a robust NAMA, e. g., setting goals, implementing related actions, ensuring sufficient human and financial resources for these actions,
Another proposal has been to establish positive and/or negative lists of project types. A positive list would include project types that are assumed to be additional and thus would not be required to undergo project-by-project testing. Positive lists would not seem to hold much promise for the transport sector. It can hardly be argued that transport measures are nearly always "additional" in the sense that they would not be undertaken if there was no reward for the emission reduction they achieve. While a negative list would exclude specific project types, it might improve the relative attractiveness of transport projects. In terms of volumes of $\mathrm{CO}_{2}$, the $\mathrm{CDM}$ is currently dominated by a few projects that achieve high emission reductions at low cost (for instance, the destruction of industrial gases). If such project types with very cheap emission reduction potential were excluded from the CDM, higher-cost options could become more attractive.

A further proposal is to include achievement of local sustainability benefits as a criterion for project registration at international level. Transport projects are particularly likely to achieve co-benefits in addition to GHG emission reductions, such as reduction of noise or local pollutants. If achievement of such cobenefits was rewarded with preferential treatment, many transport projects could gain a competitive advantage over the low-cost end-of-pipe projects that currently dominate the CDM pipeline.

\section{For future climate policy instruments it might be wise to separate the measurement of emissions and the assessment of policy implementation.}

documentation requirements, and tracking progress over time. Under a proposal of the United Nations Foundation, the Conference of the Parties could request the International Organisation for Standardisation to develop a management system standard for NAMAs. Developing countries could then devise a comprehensive climate management system according to this standard and request international certification. NAMAs developed under a certified national management system would automatically be deemed measurable, reportable, and verifiable. This approach would mirror the relationship the Conference of the Parties has with the IPCC as regards the development of emission inventory requirements (Kimble and Niederberger 2009).

\section{Reforming the Clean Development Mechanism}

One proposal to facilitate the development of CDM projects has been to establish multi-project baselines rather than specific baselines for each project. These would essentially be sectoral benchmarks for specific project activities. For example, for activities aiming at modal shifts, project developers could apply national average vehicle occupancy rates. Sectoral benchmarks for indicators like occupancy rates and distances covered could reduce methodological problems and the costs of monitoring energy savings, i.e., reductions in GHG emissions.

\section{Introduction of New Emission Trading Mechanisms}

Apart from reforms of the CDM, it has also been proposed to introduce new emission trading mechanisms that go beyond the project-by-project approach of the CDM and instead reward reductions at an aggregate level. One proposal is to issue emission credits for successful NAMAs, i.e., to reward the introduction or tightening of a policy, such as a vehicle efficiency standard.

A further proposal, sectoral approaches, would assess the development of emissions at sectoral level, for example for the transport sector of a country or a city. There are two options for sectoral approaches:

- One would retain the baseline-and-credit model of the CDM. That is, a baseline would be defined for the transport sector and emission credits awarded if actual GHG emissions are kept below the baseline.

- As for the second option, the EU has advocated that it may be possible to agree on absolute emission caps, at least for some sectors in some developing countries. Caps for the transport sector could be defined in a country, region, or city, and the respective government would then receive emission allowances according to the cap. If the government then managed to keep transport-related GHG emissions below the cap, they would generate a surplus of allowances which they could sell. 
Alternatively, the cap could be broken down to private entities through a cap-and-trade emission trading system.

Both sectoral and policy-based crediting may lend themselves much better to transport than the current project-based CDM (Browne et al. 2005, pp. 64-66; Wittneben et al. 2009). These approaches could potentially provide stimulus for non-Annex I countries to introduce policies and measures that redirect investments. In addition, sectoral and policy-based crediting imply the establishment of the baseline and of additionality at an aggregate level. They would thus have the advantage of removing the necessity to determine the additionality of individual investment decisions, which is almost impossible in most cases.

These approaches do, however, pose new challenges for baseline setting and additionality testing. Policy-based crediting poses the challenge of distinguishing the signal from the noise. The sector-based approach removes this difficulty by simply assessing the performance of a sector as a whole instead of trying to evaluate individual projects or policies. A cap-based approach has the added advantage of not being confronted with the additionality problem at all. Under a cap-based approach, trading involves actual emissions and not emission reductions determined on the basis of a hypothetical baseline.

\section{It is questionable whether emission trading mechanisms will provide an incentive to implement effective policies.}

However, defining the baselines or caps as well as quantifying emissions and reductions for both policy and sector approaches would necessitate reliable emission inventories and projections for the countries or at least for the sectors covered. While emission inventories could be established relatively easily based on data from transport fuel producers and importers, accurate projections of future transport emissions would be difficult. Schneider and Cames (2009) discuss in detail the many difficulties connected with establishing robust sectoral baselines. Emission monitoring would also need to be reliable. At the moment, probably only a few, if any, developing countries dispose of the necessary technical capacity and data infrastructure. This would also mean improving data availability from the transport sector.

Finally, Ward et al. (2008, p. 71) question if sectoral mechanisms would in fact provide a strong incentive for developing countries to implement climate-friendly policies. As emission reductions cannot be predicted exactly and prices on the emission trading market are volatile, governments would be unable to predict accurately the amount of revenue to be had. This may be a serious problem for governments as they "are not investing in policies and measures to speculate in carbon markets".

\section{The Way Forward: Suggestions for Copenhagen}

\section{Principles}

Suggestions for a future climate agreement should be based on lessons learnt from sustainable transport systems and from climate policy. From a sustainable transport perspective, two principles are recommended when setting a framework in developing countries to prevent repetition of unsustainable trends experienced in the industrialised world:

- go beyond project-based approaches and include policy (packages) to achieve sustainable transport systems that reduce transportation needs and offer high-quality alternatives to cars and trucks;

- provide capacity and funding that enable effective long-term action.

From a climate perspective, there are two further principles to consider:

- provide appropriate and predictable resources;

- ensure environmentally sound and cost-effective measures.

Developing countries indicated in Bali that they are willing to undertake nationally appropriate mitigation actions (NAMAs) and move beyond current efforts. Such NAMAs should include quantitative elements. To reduce transport-related GHG emissions, it is necessary to include requirements for a sectoral breakdown of actions in the Copenhagen agreement, be it designing an open registry for NAMAs or setting up national low-carbon development strategies. Even if no specific numbers or measures are set, the requirement of having a substantial share of reductions from the transport sector could be included in the guidelines for the development of NAMAs. Also, the debate about possible NAMAs should start as soon as possible.

\section{Funding Sustainable Transport for Developing Countries}

It is crucial to provide developing countries with sufficient financial flows for investments in order to support their mitigation activities. The Bali Action Plan asks for adequate financial support from industrialised countries for developing countries. If funding instruments do not set incentives to include complex and less cost-effective measures, transport mitigation actions will continue to be underrepresented for the reasons stated above. There are two options to link funding to NAMAs: 1. emission trading or 2. climate funds.

\section{Emission Trading}

Emission trading mechanisms like the CDM that allow offsetting of industrialised countries' emission targets may be a major source of funding and should not exclude transport activities. However, it cannot be expected that the project-oriented approach of the CDM will be a major trigger for sustainable transport. Only projects with clear boundaries and few stakeholders involved may overcome existing barriers. Linking policies to the emission trading market would further exacerbate the additionality prob- 
lems of the CDM post-2012. It is almost impossible to define whether policies would have been implemented in the absence of the climate regime.

Also, many problems with the CDM in general are due to failings in the mechanism's design, e.g., the unattractiveness of more complex projects. Removing these failings, for example through standardised baselines, may also promote CDM transport projects, especially as there are many co-benefits for local decision makers. Still, demonstrating additionality and quantifying emission reductions will remain challenging.

Sectoral approaches are a promising way to improve the environmental integrity of emission trading with developing countries. These may either be subnational or national "no-lose" targets, or absolute emission caps. No-lose targets are characterised by the fact that missing the target does not lead to facing a penalty. They can be set significantly below business-as-usual projections. Exceeding a no-lose target requires a certain contribution by developing countries. Absolute caps would completely remove the additionality problem, but they are usually associated with penalties, which will probably not be acceptable for most developing countries.

However, methodological problems regarding baseline establishment or cap setting and measuring actual emissions would remain. Plus, due to the volatility of carbon prices, it is questionable whether emission trading mechanisms would indeed provide a strong incentive for governments to adopt strong policies and measures.

Moreover, if emission trading was to be the main vehicle to financially support emission reductions in developing countries, industrialised countries would have to significantly lower their emission targets in order to generate the necessary demand for emission allowances from developing countries. Höhne et al. (2008) suggest that industrialised countries would need to commit to emission reductions of an aggregate 45 percent below 1990 levels. This is already based on the assumption that developing countries would themselves mobilise mitigation options with

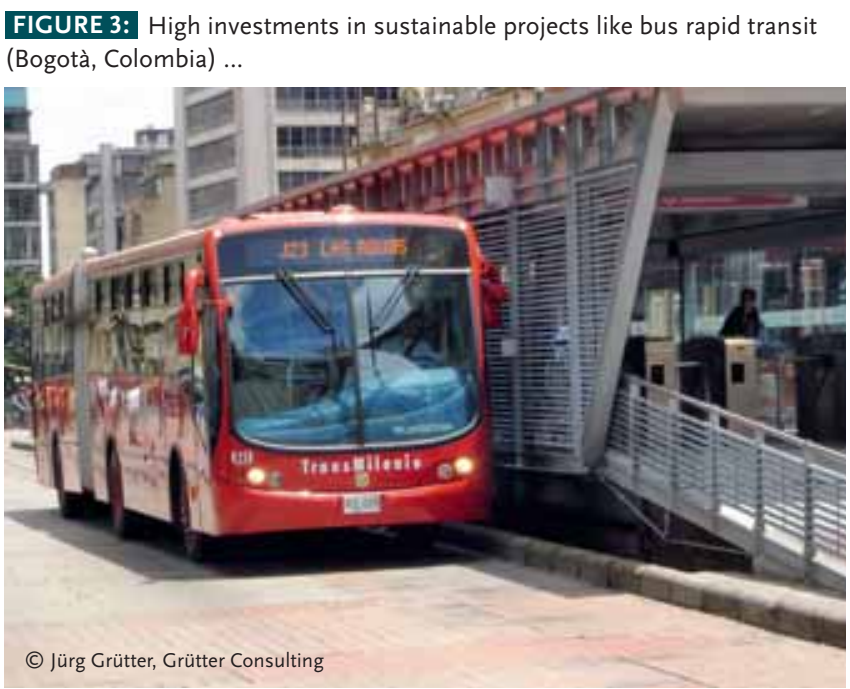

negative or low costs, which account for half of their mitigation potential as estimated by Höhne et al. Current mitigation proposals by industrialised countries add up to a range of ten to 24 percent below 1990 levels, depending on the outcome of the post2012 negotiations (Levin and Bradley 2009).

\section{Fund-Based Approaches}

Funding for NAMAs not linked to emission trading would achieve additional emission reduction efforts by developing countries that would not be counted towards industrialised countries' reduction obligations. Hence, from a climate perspective, less methodological requirements to quantify emission reductions (e.g., to determine additionality) would be needed.

To guarantee adequate coverage of transport, a carbon fund or funds should include a dedicated transport window. The fund should not only finance policies but also sustainable transport projects at local level. High investments in sustainable projects like bus rapid transit (figure 3) or light rail transit (figure 4) show that there is a strong interest among local stakeholders to improve transport systems. The difficulties of the CDM's project-based approach are more a specific problem of the CDM procedure than a general one of project-based activities. Quite the contrary, political experience at local level shows that decision making is very often bottom-up, project-related and not driven by comprehensive development strategies in a top-down manner (Dalkmann and Bongardt 2004). A fund could combine adequacy and feasibility: It could be adequate because it could enable finance for projects that are generally identified as part of low-carbon transport systems, e.g., bus rapid transit systems, bicycle networks, or compact city-type land use planning. It could be feasible because measuring, reporting, and verification could be fulfilled more easily than for emission trading. Since emission reductions achieved under a fund-based approach would not be used to offset emissions in industrialised countries, from a climate perspective additionality testing would not need to be as stringent as under an emissions trading approach.

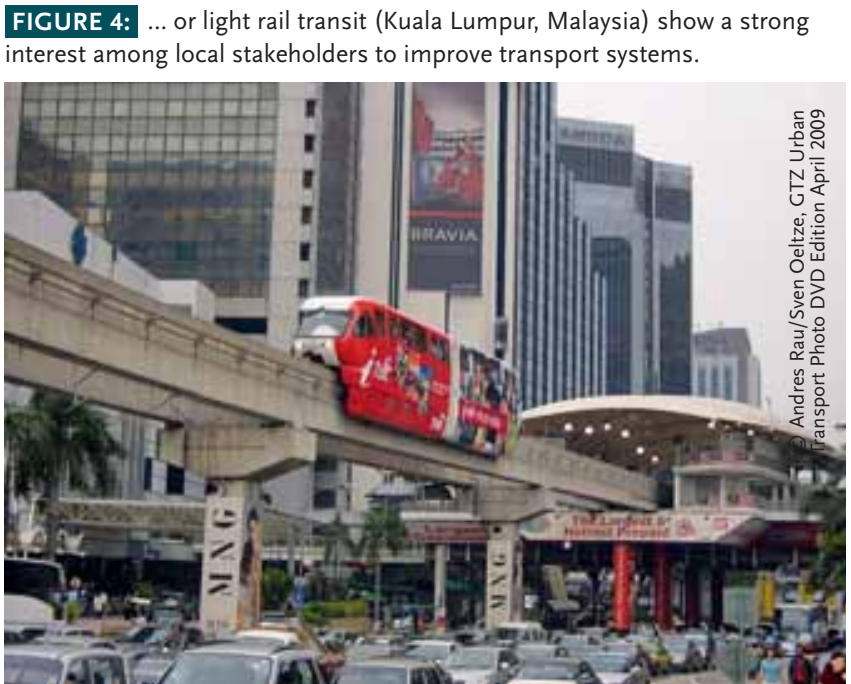


These advantages could only be exploited, however, if new mechanisms avoided the GEF's approach of trying to calculate incremental costs exactly. Designing a mitigation fund should therefore include streamlined provisions for determining incremental costs. Possible options include:

- simplified criteria and procedures for defining incremental costs;

- disbursement of funds on a country rather than action basis and based on capability criteria;

- a positive list of measures including a certain, predefined percentage of co-funding through the mitigation fund. Policies on this list would be eligible for funding and include simple mechanisms for estimating the GHG reduction potential and ensuring that the policies are implemented as described.

The political will of industrialised countries to provide substantial public funding is currently as low as their will to commit to ambitious emission targets. But if political will can be mobilised, based on the above considerations a fund-based approach would hold more promise of actions promoting sustainable transport in developing countries and emerging economies than financing through emission trading.

\section{References}

Browne, J., E. Sanhueza, E. Silsbe, S. Winkelman, C. Zegras. 2005. Getting on track: Finding a path for transportation in the CDM. Final Report, March 2005. Winnipeg: International Institute for Sustainable Development.

Dalkmann, H., D. Bongardt. 2004. Case study - The German Federal Transport Infrastructure Planning (FTIP). In: Analysing strategic environmental assessment - Towards better decision-making. Edited by P. Caratti, H. Dalkmann, R. Jiliberto. London: Edward Elgar. 123-153.

GEF (Global Environment Facility). 1993. Implementing the FCCC, Incremental Costs and the Role of the GEF. Working Paper 4. Washington, D. C.: GEF.

GTZ (Deutsche Gesellschaft für Technische Zusammenarbeit). 2007. Transport and climate change. A sourcebook for policy-makers in developing cities: Module 5e. Eschborn, Germany: GTZ.

Höhne, N. et al. 2008. Proposals for contributions of emerging economies to the climate regime under the UNFCCC post-2012. Final report on behalf of the German Federal Environment Agency. Dessau: Umweltbundesamt.

IEA (International Energy Agency). 2008 a. $\mathrm{CO}_{2}$ emissions from fuel combustion. Paris: IEA.

IEA. 2008b. World energy outlook 2008. Paris: IEA.

IPCC (Intergovernmental Panel on Climate Change). 2007 a. Climate change 2007: Mitigation. Contribution of Working Group III to the fourth assessment report. Edited by B. Metz et al. Cambridge, UK: Cambridge University Press.

IPCC. 2007b. Climate change 2007: Synthesis report. Contribution of Working Groups I, II and III to the fourth assessment report. Edited by R. K. Pachauri, A. Reisinger. Geneva: IPCC.

Kern, K. 1997. Ansätze einer innovativen und integrativen Mobilitätspolitik in den USA. In: Sektorale Umweltpolitik - Analysen im Industrieländervergleich. Edited by L. Metz, M. Jänicke. Berlin: edition sigma. 133-164.

Kimble, M., A. Niederberger. 2009. Ensuring "MRVable" national actions: An $M R V$ model with a focus on continual improvement in climate performance. Washington, D. C.: United Nations Foundation.

Levin, K., R. Bradley. 2009. Comparability of annex I emission reduction pledges. WRI Working Paper. Washington, D. C.: World Resources Institute.

Sanchez, S. 2008. Reforming CDM and scaling-up. Finance for sustainable urban transport. In: A reformed CDM - Including new mechanisms for sustainable development. Edited by K. H. Olsen, J. Fenhann. Perspectives Series 2008. Roskilde, DK: UNEP Risoe Center. 111-126.
Schneider, L., M. Cames. 2009. A framework for a sectoral crediting mechanism in a post-2012 climate regime. Report for the Global Wind Energy Council. Berlin: Öko-Institut.

Sterk, W., C. Arens. 2008. Die projektbasierten Mechanismen CDM QJIEinführung und praktische Beispiele. Reihe Umweltpolitik. Berlin: Bundesministerium für Umwelt, Naturschutz und Reaktorsicherheit.

UN (United Nations). 1992. United Nations Framework Convention on Climate Change. New York, NY: UN.

UN. 1998. Kyoto Protocol to the United Nations Framework Convention on Climate Change. New York, NY: UN.

UNFCCC (United Nations Framework Convention on Climate Change). 2007. Investment and financial flows to address climate change. Bonn: UNFCCC.

UNFCCC. 2008. Bali Action Plan. Decision 1/CP.13. Report of the conference of the parties on its thirteenth session, held in Bali from 3 to 15 December 2007. Addendum, part two: Action taken by the conference of the parties at its thirteenth session, FCCC/CP/2007/6/Add.1, 14 March 2008. Bonn: UNFCCC.

UNFCCC. 2009. Distribution of registered project activities by scope. http://cdm.unfccc.int/Statistics/Registration/RegisteredProjByScopePieC hart.html (accessed October 16, 2009).

Ward, M. et al. 2008. The role of sector no-lose targets in scaling up finance for climate change mitigation activities in developing countries. Prepared for the International Climate Division, Dept. for Environment, Food and Rural Affairs (DEFRA), United Kingdom. www.sectoral.org/images/ presentations/defra_paper\%20on\%20sector\%20no\%20lose\%20targets_ final.pdf (accessed November 10, 2009).

Wittneben, B., D. Bongardt, H. Dalkmann, W. Sterk, C. Baatz. 2009. Integrating sustainable transport measures into the Clean Development Mechanism. Transport Reviews 29: 91-113.

Yamin, F., J. Depledge. 2004. The international climate change regime. A guide to rules, institutions and procedures. Cambridge, UK: Cambridge University Press.

Submitted August 5, 2009; revised version accepted October 27, 2009.

Daniel Bongardt

Born 1973 in Düsseldorf, Germany. Studies in sociology, political science, and media science at the Universities of Halle (Germany), Lund (Sweden), and Duisburg (Germany). From 2001 to 2009 research fellow at the Wuppertal Institute. Since 2009 transport policy advisor at the German Technical Cooperation (GTZ). Focus: transport and climate change including the initiative Bridging the Gap: Pathways for Transport in the Post-2012 Process.

\section{Wolfgang Sterk}

Born 1976 in Cologne, Germany. M. A. in history of international relations from the London School of Economics and Political Science. Employed at the Wuppertal Institute since 2002. Focus: market-based climate policy instruments

(Clean Development Mechanism, Joint Implementation, EU emissions trading); the post-2012 climate regime.

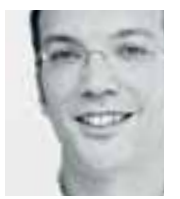

\section{Frederic Rudolph}

Born 1980 in Gießen, Germany. Studies in spatial planning at the University of Technology Dortmund (Germany) and the Ecole d'Architecture Montpellier (France). Employed at the Wuppertal Institute since 2007. Focus: sustainable transport policy and planning in developing countries and emerging economies; the post-2012 climate regime.

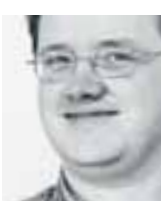

